\title{
Bandwidth Improvement
}

\section{for Compact Microstrip Patch Antenna Using Metamaterials}

\author{
T. Bougoutaia, D. Khedrouche* And A. Hocini
}

Laboratoire d'Analyse des Signaux et Systèmes, Department of Electronics, Mohamed Boudiaf University of M'sila, B.P. 166, Route Ichebilia, M'sila, 28000, Algeria

\begin{abstract}
An improved ultra-wideband (UWB) and high gain rectangular microstrip antenna is specifically designed in this paper using planar metamaterial based on double-ring resonators (DRR). The antenna has three doublering resonators (DRRs) etched on the metal patch, and a partial ground plane so that the impedance matching characteristics of the antenna are much better. The $-10 \mathrm{~dB}$ impedance bandwidth of the proposed antenna is 2.33-16.96 GHz. The antenna is promising for many applications such as WiMAX (2500-2690 MHz), Bluetooth $(2400-2480 \mathrm{MHz})$ and UWB $(3.1-10.7 \mathrm{GHz})$ applications. In addition, the proposed antenna has an average gain of $4.24 \mathrm{~dB}$ and a peak gain of $6.87 \mathrm{~dB}$ at $12.2 \mathrm{GHz}$.
\end{abstract}

DOI: 10.12693/APhysPolA.129.538

PACS/topics: 84.40.Ba, 81.05.Xj, 78.67.Pt, 84.40.Ua, 84.40.Dc, 04.40.Nr

\section{Introduction}

Demand for wireless communications and portable compact wireless communications devices continues to grow, and designers everywhere are grappling with ways to make these devices smaller. One of the most important components in any wireless communications system is the antenna, which should be compact but also provide high efficiency, generous gain, and broadband operation. Among the antennas that received the greatest interest during the last decades we find the microstrip patch antenna. The microstrip antenna benefits from several advantages like low in profile, light in weight, compact and conformable in structure, and easy to fabricate and to be integrated with solid-state devices [1]. But the microstrip antennas suffer from a major handicap of narrow bandwidth. Recently, several techniques and tests were conducted to improve the bandwidth, and the literature is prolific in this topic [2-4].

During the last decade new materials appeared, known as metamaterials, they are widely used for many applications. These specifically designed composite structures have some special properties which cannot be found in natural materials. Metamaterials are also known as double negative (DNG) materials or left handed materials (LHM), and were first introduced by Veselago [5] in 1967, when he made a theoretical speculation of this artificial material that exhibits negative permittivity and negative permeability. Thirty two years later, on 1999, Pendry and his colleagues [6] added more information. They concluded that, for obtaining negative permittivity and negative permeability, array of metallic wires and split ring resonators can be used respectively. Based on this

\footnotetext{
* corresponding author; e-mail: djamel.khedrouche@univ-msila.dz
}

information a structure has been made by Smith and his colleagues in 2001 [7], which was a composition of split ring resonator and thin wire. Nowadays, there has been a growing interest in metamaterials with negative permittivity and permeability as candidates for design of novel microstrip antenna [8-10].

In this paper, a UWB microstrip antenna with higher gain, wider bandwidth and small size is proposed and designed. This metamaterial microstrip patch antenna is designed, simulated and optimized over high frequency structures simulator (HFSS) which is based on finite element method numerical technique, and the computer simulation technology (CST) microwave studio (MWS), which is based on finite integration technique. The configuration of the proposed antenna with dimensions of $26 \times 35 \mathrm{~mm}^{2}$ is shown in Fig. 1. The bandwidth of this antenna is $14.36 \mathrm{GHz}$ for $\left|S_{11}\right|<-10 \mathrm{~dB}$, and it achieves maximum gain of $6.87 \mathrm{~dB}$, while exhibiting a voltage standing wave ratio (VSWR) that remains below 2 in the operating band.

The work reported in this paper demonstrates an important improvement in the performances of the proposed antenna so that, it can operate in the fcc bandwidth authorization with high efficiency.

\section{Antenna design}

The geometry of the proposed compact metamaterial antenna is illustrated in Fig. 1; it is printed on a FR4epoxy substrate with a thickness of $1.6 \mathrm{~mm}$ and permittivity of 4.4 . The width of the microstrip feed line is fixed at $3 \mathrm{~mm}$ to achieve a $50 \Omega$ characteristic impedance. The overall antenna dimension is $26 \times 35 \mathrm{~mm}^{2}$. The area of the upper patch mounted is $14 \times 20 \mathrm{~mm}^{2}$, with three units periodic of double-ring resonators (DRRs) etched on it. The left-handed characteristics of these patterns were demonstrated in [11] and will not be discussed further here. On the other side of the substrate, we have the partial ground plane with dimension of $26 \times 10 \mathrm{~mm}^{2}$. 

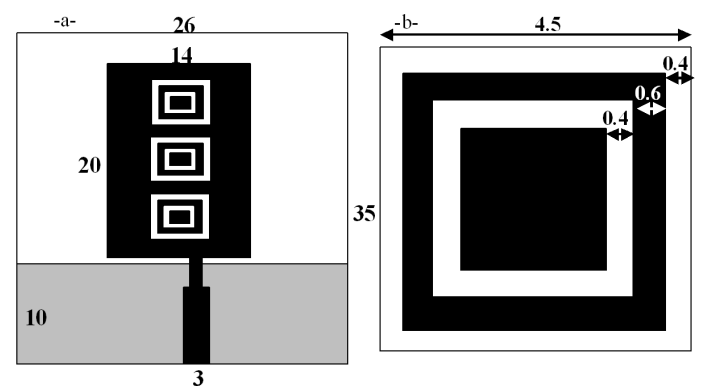

Fig. 1. (a) Proposed antenna, (b) unit cell. All the dimensions are in $\mathrm{mm}$.

\section{Results and discussion}

The microstrip patch antenna structure which is shown in Fig. 1 is designed, simulated over HFSS and CST, where the obtained results are presented and discussed.

An intensive optimization study was conducted to gauge the effect of each parameter on the performance of the antenna but will not be shown here for brevity. This optimization has been carried out by changing one of the parameters without modifying the others. The final optimal values of the antenna are depicted in Fig. 1.

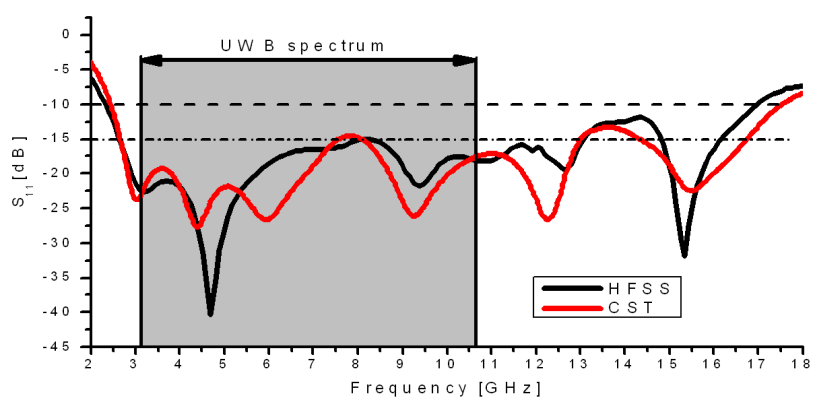

Fig. 2. Simulated return loss $\left(S_{11}\right)$ curve versus frequency of proposed antenna.

Figure 2 shows the return loss $\left(S_{11}\right)$ curve of the designed antenna obtained by HFSS and CST simulators. It can be seen that the two curves are in agreement in the considered range of frequency band. From the results in Fig. 2, it is seen that the proposed antenna has an UWB based on a $-10 \mathrm{~dB}$ return loss from $2.33 \mathrm{GHz}$ to $16.96 \mathrm{GHz}$, and it has a multi-band characteristic in the UWB spectrum. Those resonant frequencies are located at about 3.1, 4.6, 9.3, 12.3, and $15.3 \mathrm{GHz}$. This result proves the multiband characteristics of the proposed antenna. Moreover, we can notice that the proposed antenna can operate in the fcc bandwidth authorization with high efficiency, from $2.64 \mathrm{GHz}$ to $13 \mathrm{GHz}$ where the proposed antenna satisfies the return loss $\left(S_{11}\right)$ requirement of less than or equal to $-15 \mathrm{~dB}$.

The simulation results for VSWR for the frequency range from 2.33 to $16.96 \mathrm{GHz}$ is shown in Fig. 3 . The VSWR of the antenna is closely related to the return loss. The value of VSWR can be seen to be within 1 to 2 in the operating range.

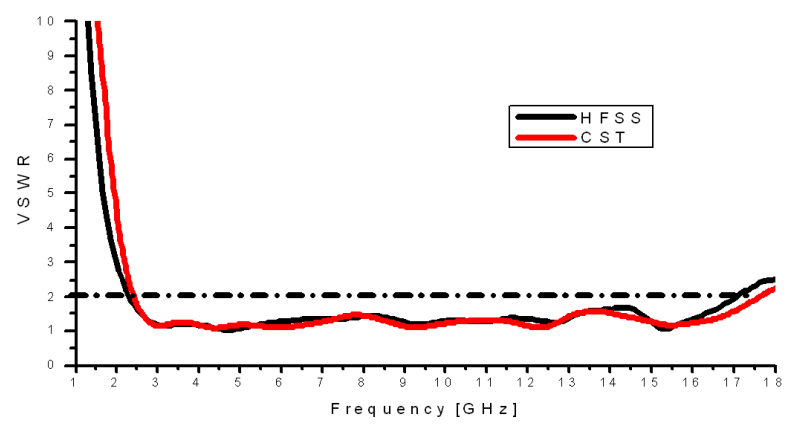

Fig. 3. VSWR versus frequency of designed antenna.

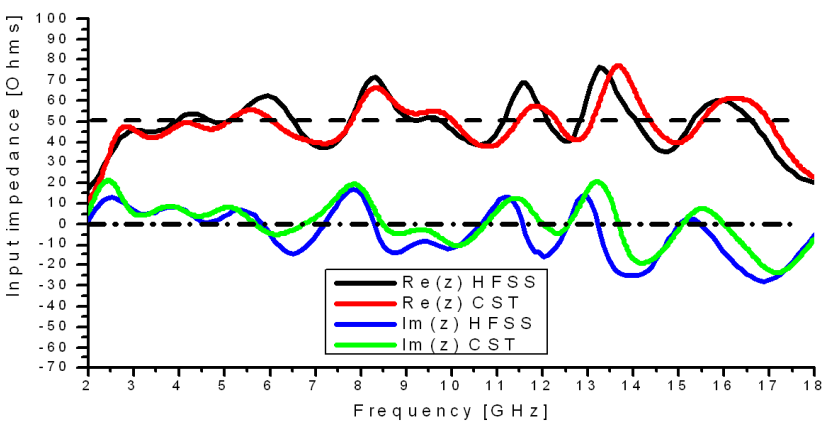

Fig. 4. Input impedance versus frequency.

Figure 4 shows the resistance and reactance behavior of the antenna as a function of frequency. It shows that the low $S_{11}(<-10 \mathrm{~dB})$ always occurs over the frequency range when the input impedance is matched to $50 \Omega$, i.e. the input resistance is close to $50 \Omega$ while the input reactance is not far from zero. At operating frequency, the resistance is closed to $50 \Omega$ and the reactance closed to 0 , thus resulting in an impedance matching at the input antenna which increase the operating bandwidth.

The peak gain of the antenna, computed at the frequencies of interest, is given in Fig. 5. A lowest gain value of $1.09 \mathrm{~dB}$ is recorded at $2.3 \mathrm{GHz}$. From 7.8 to $16.9 \mathrm{GHz}$, the gain is greater than $4 \mathrm{~dB}$ and the maximum achievable gain is $6.87 \mathrm{~dB}$ at $12.2 \mathrm{GHz}$.

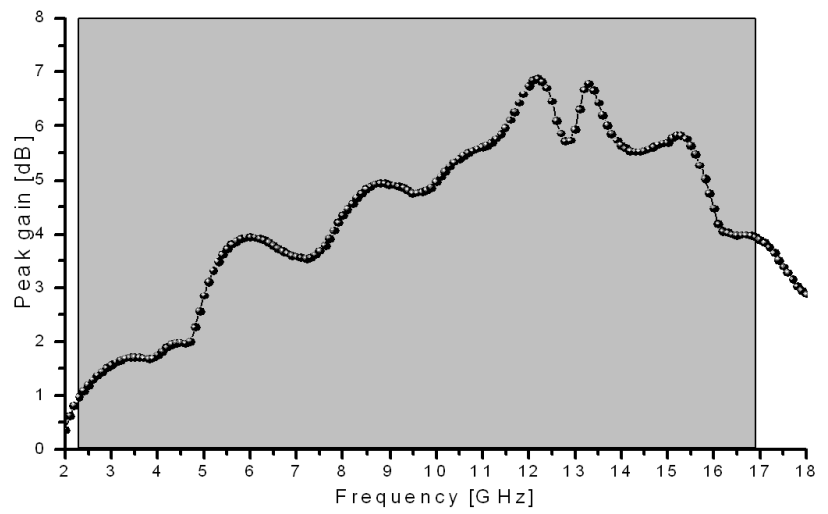

Fig. 5. Peak gain versus frequency. 


\section{Conclusion}

In this paper, an ultra-wideband and high gain rectangular microstrip antenna using planar metamaterial based on complementary double-ring resonators, is successfully designed and optimized over HFSS and CST simulators.

The proposed microstrip patch antenna is compact, miniature, cost effective, simple to manufacture, and has an ultra wide band from $2.33 \mathrm{GHz}$ to $16.94 \mathrm{GHz}$, which represents $151 \%$ fractional bandwidth. In addition, the proposed antenna has an average gain of $4.24 \mathrm{~dB}$ and a peak gain of $6.87 \mathrm{~dB}$ at $12.2 \mathrm{GHz}$. This metamaterial microstrip antenna is suitable for many electronics applications such as WiMAX, Bluetooth, and UWB application. Moreover, the proposed antenna can operate in the fcc bandwidth authorization with high efficiency.

\section{References}

[1] Y.T. Lo, D. Solomon, W.F. Richards, IEEE Trans. Antennas Propagat. 27, 2 (1979).
[2] D. Sarkar, K.V. Srivastava, K. Saurav, IEEE Antennas Wireless Propagat. Lett. 13, 396 (2014).

[3] H.-W. Liu, C.-H. Ku, T.-S. Wang, C.-F. Yang, IEEE Antennas Wireless Propagat. Lett. 9, 397 (2010).

[4] M. Abbosh, M.E. Bialkowsky, IEEE Trans. Antennas Propagat. 56, 1 (2008).

[5] V.G. Veselago, Sov. Phys. Usp. 10, 509 (1968).

[6] J.B. Pendry, A.J. Holden, D.J. Robbins, W.J. Stewart, IEEE Trans. Micro Tech. 47, 11 (1999).

[7] R.A. Shelby, D.R. Smith, S. Schultz, Science 292, 5514 (2001).

[8] L.W. Li, Y.N. Li, T.S. Yeo, J.R. Mosig, O.J.F. Martin, Appl. Phys. Lett. 96, 164101 (2010).

[9] H. Xiong, J.-S. Hong, M.-T. Tan, B. Li, Turk. J. Electr. Eng. Comp. Sci. 21, 2233 (2013).

[10] A.M. Abbosh, M.E. Bialkowski, IEEE Trans. Antennas Propagat. 56, 1 (2008).

[11] B. Lu, Z.F. Ji, Z.G. Dong, X.W. Ping, T.J. Cui, J. Appl. Phys. 108, 3717 (2010). 